\title{
Methylprednisolone in multiple sclerosis: a comparison of oral with intravenous therapy at equivalent high dose
}

\author{
S M Alam, T Kyriakides, M Lawden, P K Newman
}

\begin{abstract}
Summary
A randomised double-blind placebo-controlled trial of intravenous methylprednisolone versus oral methylprednisolone at equivalent high dose was carried out on 35 patients with an acute relapse of multiple sclerosis (MS). After baseline evaluation each was randomly allocated to oral treatment and intravenous placebo or intravenous treatment and oral placebo, receiving $500 \mathrm{mg}$ of methylprednisolone for five consecutive days and with reassessment at days five and twenty-eight. There was no significant difference in response when disability or functional scores were compared in the two groups. Adverse effects were minor and equally distributed. In this study oral treatment with methylprednisolone was as effective as intravenous treatment in acute relapse of $\mathrm{MS}$.
\end{abstract}

$(尹$ Neurol Neurosurg Psychiatry 1993;56:1219-1220)

The influence of short courses of corticosteroid therapy in relapsing multiple sclerosis (MS) has been studied in placebo-controlled trials using $\mathrm{ACTH}^{1}$ and intravenous methylprednisolone $\mathrm{e}^{23}$ and in comparative studies. ${ }^{4-6}$ There is some suggestion that high doses of steroids may be more effective than lower doses $^{7}$ but this has not been convincingly demonstrated. Many clinicians, influenced by the published material and their own experience, now routinely use high dose intravenous methylprednisolone for patients in relapse. This form of treatment is inherently esis that an equivalent dose of oral methylprednisolone is no less effective.

Department of Neurology, Middlesbrough General Hospital, Ayresome Green Ayresome Green
Lane, Middlesbrough, Cleveland TS5 5AZ, UK

$S$ M Alam

T Kyriakides

$M$ Lawden

P K Newman

Correspondence to:

Dr Newman

Received 5 June 1992 and in final revised form 26 January 1993.

Accepted 29 January 1993

Thirty-eight patients with clinically definite MS were admitted to the trial. Each presented in relapse, which was defined as symptomatic deterioration within the previous four weeks of sufficient severity to require steroid treatment and without improvement at the time of entry. Two patients withdrew from the study and one patient was withdrawn due to inadvertent 'unblinding'; all three had been randomised to receive oral medication and inconvenient. We have examined the hypoth-

intravenous placebo. Another patient was allocated to oral treatment but then withdrawn as he did not fulfil the criteria for relapse. The 35 patients studied, comprising nine males and 26 females, had a mean age of 41.5 years (range 19-72) and a mean duration of disease of 5.4 years (range $0 \cdot 1-27$ ). Informed consent was obtained from each patient and the study was approved by the local ethics committee.

Following randomisation, each patient received either $500 \mathrm{mg}$ of intravenous methylprednisolone in $100 \mathrm{ml}$ of normal saline by slow intravenous infusion together with five placebo tablets, or $100 \mathrm{ml}$ of placebo intravenously with five $100 \mathrm{mg}$ tablets of methylprednisolone orally, for five days. All patients were scored by a "blind" assessor at days 0,5 and 28 using the disability and functional rating score devised by Kurtzke; ${ }^{8}$ specific enquiries were made regarding possible adverse effects.

\section{Results}

Thirty-five patients were randomised to either intravenous treatment and oral placebo $(\mathrm{N}=20)$ or oral treatment and intravenous placebo $(\mathrm{N}=15)$. There were no significant differences between the two groups in age, sex distribution, duration of disease or disability score at entry. There was no significant over representation in either group of any particular clinical manifestation. The Kurtzke disability score had improved at day 28 in 16 of the 20 in the intravenous group, mean score of the whole group falling from 4.85 to 3.50 , and in 10 of the 15 in the oral group, mean score falling from 4.80 to 3.67 . Statistical analysis using Student's $t$ test and the Mann-Whitney rank sum test, indicated a clear improvement in both groups over the course of the study $(p<0.01)$ but no significant differences between the two groups at days 5 and 28 .
Table Clinical details of trial patients. Values are mean (SD)

\begin{tabular}{lll}
\hline & $\begin{array}{l}\text { Injection } \\
(20)\end{array}$ & $\begin{array}{l}\text { Tablets } \\
(15)\end{array}$ \\
\hline Male: Female & $4: 16$ & $4: 11$ \\
Age (years) & $41 \cdot 6(12 \cdot 8)$ & $41 \cdot 3(13 \cdot 6)$ \\
Duration of disease (years) & $6 \cdot 5(7 \cdot 4)$ & $3 \cdot 8(3.5)$ \\
Disability score & $4 \cdot 85(1 \cdot 9)$ & $4 \cdot 8(1 \cdot 9)$ \\
\hline
\end{tabular}


There were no major side effects in either group. Minor side effects including headache, indigestion, acne, dizziness, flushed feeling, phlebitis, ankle oedema and mild depression were equally distributed in both groups. A metallic taste after injection was only present in the intravenous group. There was no increase in gastrointestinal symptoms in the group that received methylprednisolone orally.

\section{Discussion}

Most neurologists use steroid therapy in one form or another to treat patients with MS in relapse, although some hold the view that any benefit is at best only marginal. ${ }^{9}$ Intravenous methylprednisolone has been used successfully for several years but this form of therapy may be inconvenient for the patient and wasteful of hospital resources. This study suggests that oral methylprednisolone at an equivalent high dose is as effective and safe as intravenous treatment. The treatment response was the same in the orally treated patients as in the intravenous group. There were no serious adverse effects in either group; the frequency of minor side effects was equal and in particular there was no excess of upper gastrointestinal reactions in the oral group.

In an earlier controlled trial of intravenous methylprednisolone a significant improvement was seen compared with placebo when 22 patients in relapse were evaluated. ${ }^{3}$ Our study had the power to detect a $25 \%$ difference in disability grade improvement between the oral and intravenous treatments but would have required 98 randomisations to detect a $10 \%$ difference. Thus a large study is desirable which could include another arm of low dose prednisolone and should be ideally placebo controlled.

This experience in patients with MS parallels similar findings when high dose oral methylprednisolone has been evaluated in patients with rheumatoid arthritis ${ }^{10}$ and in children with idiopathic thrombo cytopenia purpura. ${ }^{11}$ Oral medication has obvious logistic advantages over intravenous therapy, and our study suggests that in MS it is as safe and no less effective.

We thank Sandra Green for statistical advice.

1 Co-operative study in the evaluation of therapy in multiple sclerosis. ACTH vs placebo final report. Neurology 1970;20(Suppl): 1-59.

2 Durrelli L, Cocitu D, Riccio A, et al. High dose intravenous methylprednisolone in the treatment of multiple sclerosis: Clinical immunological correlation. Neurology 1986;36:238-43.

3 Milligan NM, Newcombe R, Compston DAS. A double blind controlled trial of high dose methylprednisolone in patients with multiple sclerosis. 1. Clinical effects. patients with multiple sclerosis. 1. Clinical
$\mathcal{H}$ Neurol Neurosurg Psychiatry 1987;50:511-6.

4 Barnes MP, Bateman DE, Cleland PG, et al. Intravenous methylprednisolone for multiple sclerosis in relapse. methylprednisolone for multiple sclerosis
$\mathcal{F}$ Neurol Neurosurg Psychiatry 1985;48:157-9.

5 Abbruzzese G, Gandolfo C, Loeb C. "Bolus" methylprednisolone versus ACTH in the treatment of multiple sclerosis. Ital $\mathcal{F}$ Neurol Sci 1983;2:169-72.

6 Thompson AJ, Kennard C, Swash M, et al. Relative efficacy of intravenous methylprednisolone and ACTH in the treatment of acute relapse in MS. Neurology 1989; 39:969-71.

7 Bindoff L, Lyons PR, Newman PK. Saunders M. Methylprednisolone in multiple sclerosis: a comparative dose study. I Neurol Neurosurg Psychiatry 1988;51: 1108-9.

8 Kurtzke JF. Further notes on disability evaluation in multiple sclerosis with scale modification. Neurology multiple sclerosis

9 Goodin DS. The use of immunosuppressive agents in the treatment of multiple sclerosis. A critical review Neurology 1991;41:980-5.

10 Smith MD, Ahern MJ, Roberts-Thomson PJ. Pulse steroid therapy in rheumatoid arthritis: Can equivalen doses of oral prednisolone give similar clinical results to intravenous methylprednisolone? Ann Rheumatic Dis 1988;47:28-33.

11 Ozsoylu S, Erturk B. Oral megadose methylprednisolone for childhood acute idiopathic thrombocytopenic purpura. Blood 1991;77:1856-7. 